\title{
Comparative Study on Tribological Behavior of Graphene/Polyimide and Carbon Fibers/Polyimide Composites: A Review
}

\author{
Niyobuhungiro Daniel, Hong Liu* \\ School of Mechanical Engineering, Lanzhou Jiaotong University, Lanzhou, China \\ Email: danielniyobuhungiro@gmail.com, ^hliu@mail.lzjtu.cn
}

How to cite this paper: Daniel, N. and Liu, H. (2021) Comparative Study on Tribological Behavior of Graphene/Polyimide and Carbon Fibers/Polyimide Composites: A Review. World Journal of Engineering and Technology, 9, 26-50.

https://doi.org/10.4236/wjet.2021.91003

Received: November 9, 2020

Accepted: December 13, 2020

Published: December 16, 2020

Copyright $\odot 2021$ by author(s) and Scientific Research Publishing Inc. This work is licensed under the Creative Commons Attribution International License (CC BY 4.0).

http://creativecommons.org/licenses/by/4.0/

\begin{abstract}
Recently, graphene and carbon fibers have enticed extensive consideration in many scientific fields, they are considered by many scientists to be one of the most promising materials in the $21^{\text {st }}$ century. Due to the uniqueness of their properties was attracted to be used to reinforce polyimide. Impressive graphene properties coupled with those excellent of polyimide composites produced composites materials with good tribological properties, different contents of graphene and its derivatives tend to improve polyimide composites properties particularly friction and wear. Furthermore, nanofillers decorated graphene derivatives showed also an effect on the tribological properties of composites. Carbon fibers coupled with polyimide composites also reviewed and showed a significance in the improvement of the properties of composites materials. The results nanofillers reinforced carbon fibers/polyimide exhibit enhanced tribological properties, which can be applied in various fields. Therefore, this survey article gives an enormous review study of the tribological properties under various conditions of graphene/polyimide and carbon fibers/polyimide composites. Besides the effects of nanofillers size on tribological properties, preparation, and research challenges were also reviewed.
\end{abstract}

\section{Keywords}

Graphene, Carbon Fiber, Polyimide Composite, Tribology

\section{Introduction}

Polymer materials with lightweight, high strength, good self-lubricity, and low friction have gradually replaced some metal materials in the area of tribology and have broad application prospects. Among high-molecular-weight anti-friction 
materials, Polyimide (PI), as a kind of high-performance thermoplastic polymer, has many advantages, such as excellent mechanical properties, high-temperature resistance, low-temperature resistance, high strength, high modulus, corrosion resistance, good creep resistance, and so on. It has incomparable advantage in the field of tribology and attracts much attention [1] [2] [3].

However, as high-performance self-lubricating wear-resistant material still has a high friction coefficient and wear resistance limits its further application in high-performance fields [4]. The electrical, thermal, and mechanical properties of the composites can be improved by adding modified fillers to the polyimide matrix. Graphene and carbon fibers showed a great effect to improve significantly different properties of composites [5] [6] [7]. Graphene is the commonly used nano-reinforcing fillers, but due to its strong interlayer force, it is easy to accumulate in the matrix. Graphene has been broadly used in friction and lubrication due to its low interlaminar shear force [8]. Also, because of its unique two-dimensional structure and high specific surface area, graphene-based nanocomposites can be developed by loading different nanomaterials on its surface, which can play a synergistic role in reducing friction and resisting wear [9] [10]. Due to the uniform dispersion of Graphene oxide (GO) nanosheets and the strong interaction with the polyimide matrix, the mechanical properties, electrical conductivity, and thermal conductivity of PI/GO composite have been significantly improved [11]. Carbon fibers were also proved to enhance composites' properties, especially polymers. Different carbon fibers (CF) were introduced into PI composites and showed improved mechanical, electrical, thermal, and tribological properties to the extent. CF is still now accredited as the most significant industrial materials in modern-day science and technology. Considering its strength, CF-based polymer composites first appeared in the 1960s, and gradually extended to a variety of applications, such as the automotive industry, civil construction, aerospace application, aviation, and off-shore [12] [13] [14]. This paper mainly reviewed the introduction of graphene and CF into polyimide composites for tribological applications under various conditions. Therefore, the preparation and the properties of polyimide, graphene, and carbon fiber are briefly discussed. Finally, the challenges faced in the preparation of graphene/PI and $\mathrm{CF} / \mathrm{PI}$ composites were discussed.

\section{Friction and Wear}

The friction and wear processes for composites materials are complex due to the interaction of two or more materials in the fracture process leading to the formation of a wear particle. There are four basic mechanisms: adhesion, abrasion, corrosion, and surface fatigue, they are familiarly used to define the wear of materials [15]. Operating systems to be stable depending on wear and friction occurred during processing. For instance, to maintain good processing, a variation of wear rate and friction coefficient has to be controlled. Meanwhile, to improve the performance of friction materials, alloying elements, reinforced fibers, and 
other materials, have been studied to formulate materials with excellent properties. Furthermore, the composition and microstructure of material have a great influence on the tribological characteristics of materials. Metals, ceramic, polymers, etc. are used for tribological applications. For metal friction materials, the combination of various elements can improve friction and wear properties [16] [17] [18]. Dyachkova et al. studied the properties of CuSn alloy reinforced by infiltration. The addition of $\mathrm{Cu}$ and $\mathrm{Sn}$ can improve tribological properties. The wear resistance is 2.5 - 3.3 times lower than that of the infiltrating layer [19]. Merie et al. investigated Fe-based friction composite material by adding $\mathrm{TiO}_{2}$, by the increasing up to $6 \mathrm{wt} \%$ of $\mathrm{TiO}_{2}$ content showed also an increase of the friction coefficient, while adding $8 \mathrm{wt} \%$ of $\mathrm{TiO}_{2}$ intent in decreasing of friction coefficient, consequently wear rate decrease as increasing $\mathrm{TiO}_{2}$ contents [20]. Zhang et al. investigated the properties of different weight of $\mathrm{Ni} / \mathrm{NbSe}_{2}$ as added to copper by using powder metallurgy $(\mathrm{P} / \mathrm{M})$ process. The tribological properties of the composites were evaluated on a ball disc friction and wear tester. The results indicated that the addition of $\mathrm{Ni} / \mathrm{NbSe}_{2}$ significantly improves the tribological properties of copper matrix composites. When the content of $\mathrm{Ni} / \mathrm{NbSe}_{2}$ added to the copper matrix composite is $15 \mathrm{wt} \%$, the friction coefficient $(0.16)$ and wear rate $\left(4.1 \times 10^{-5} \mathrm{~mm}^{3} / \mathrm{N} \cdot \mathrm{m}\right)$ are very low compared with other composites [21]. The friction and wear of polymer and its composites reinforced by various materials have been improved significantly. Polyphenylene sulfide (PPS) containing nanoparticles such as alumina, $\mathrm{TiO}_{2}, \mathrm{ZnO}, \mathrm{CuO}$, and $\mathrm{SiC}$, and so on, makes the tribological properties of the composites change significantly [22] [23]. Polyetheretherketone composites coupled with various kinds of $\mathrm{SiC}, \mathrm{ZrO}_{2}$ showed an impact on friction and wear of material composite [24]. Epoxy composites enhanced with various particles such as $\mathrm{Al}_{2} \mathrm{O}_{3}$ and $\mathrm{SiC}$ changed the tribological properties of epoxy nanocomposites [25]. Therefore this review has emphasized the study of graphene and carbon fibers with different contents and conditions that emerged into polyimide and formulated materials with incredible properties.

\section{Material Characteristics}

\subsection{Graphene}

Graphene as a covalently bonded monolayer of carbon atoms with a hexagonal structure and can be transformed as zero dimension (fullerenes), 1D (Carbon nanotubes) and 3D (Graphite) (Figure 1) make the thinnest material in the world at present, and also makes it one of the world's best in properties [26]. Graphene not only has ultra-high carrier mobility, thermal conductivity, mechanical modulus ( $1 \mathrm{TPa})$, breaking strength (125 GPa), but also has high transparency, superior gas barrier, and high specific surface area. These characteristics make graphene have great potential application prospects and market value in transportation, electronic devices, energy storage, biomedical and other fields. Graphene has excellent electrical, thermal, and mechanical properties, which can be used as an ideal nanofiller for high strength conductive composites. The addition 


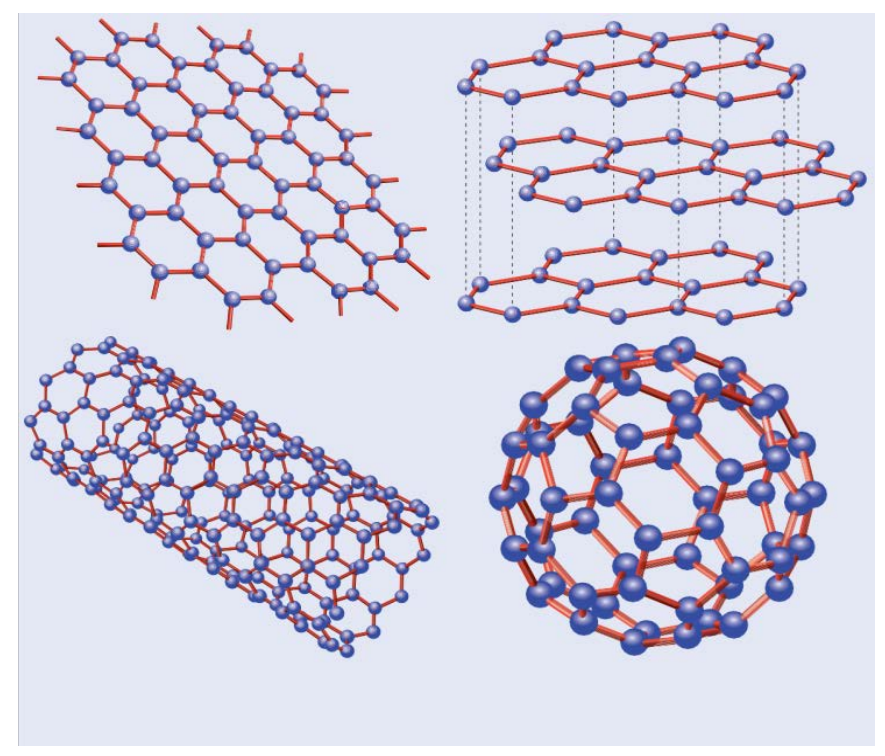

Figure 1. Graphene structure [28] [29].

of graphene can give the composite different functions, which not only shows excellent mechanical and electrical properties but also has excellent processing performance, which provides a broader application space for composite materials [26] [27] [28] [29].

\subsection{Carbon Fibers}

Carbon fiber is a new type of material with excellent processing and mechanical properties. The tensile strength and modulus of carbon fiber are about $2-7 \mathrm{GPa}$ and $200-700 \mathrm{GPa}$ respectively. The density is about $1.5-2.0 \mathrm{~g} / \mathrm{cm}^{3}$, which is related to the carbonization temperature besides the precursor structure. The carbon fiber coefficient of thermal expansion is different from other fibers. This makes carbon fiber have the highest specific strength and specific modulus among all high-performance fibers. Besides, carbon fiber has the advantages of high-temperature resistance, low-temperature resistance, good thermal conductivity, and corrosion resistance. Because of its low density, it is particularly suitable for aerospace and automotive applications [30] [31] [32].

\section{Preparation of Polyimide Matrix Composites}

\subsection{Polyimide/Graphene Oxide Composites Preparation}

There are many preparation methods to prepare polymer/graphene oxide nanocomposites such as solution mixing, melt mixing, and in-situ polymerization. Different kinds of polymer graphene composites can be prepared by using the above three methods. Graphene and its derivatives, as two-dimensional nanofillers, have significant effects on the thermal, flame retardant, electrical, mechanical, and tribological properties of polymer composites [33]. Polyimide (PI) matrix can be prepared by different methods; the polymer/graphene composites obtained by in-situ polymerization have stronger interfacial interaction, there- 
fore, its comprehensive performance has been significantly improved. Liu, H. et al. developed a PI matrix using in-situ polymerization. PI resin was analyzed using 4-phenylethynylphthalic anhydride (PEPE), 4,4'-Oxydianiline (ODA), and 4-phenylethynylphthalic anhydride (ODPA) monomers mixture with methanol $(\mathrm{MeOH})$ and 1-Methyl-2-pyrolidinone (NMP). In preparation for the PI/GO integration, GO was introduced to the resin solution at different weight tests and subjected to 3 hours of ultra-sonication to ensure uniform dissolution [34]. Choi et al. prepared PI/GO nanocomposites using the In-situ polymerization method by combining different monomers such as 2,6-Diaminoanthracene (AnDA), $5(4 \mathrm{H})$-tetrone (DAn), dimethylacetamide (DMAc), and so on. Firstly (Figure 2) GO powder using sonication was placed into DMAc; and AnDA was added to modify the GO. Finally, a mixture of DAn, AnDA, and AnDA-GO in DMAc was stirred to produce poly (amic acid)-GO (PAA-GO), which was then chemically imidized to obtain PI-GO [35].

\subsection{Carbon Fibers/Polyimide Composites Preparation}

Fiber-based polymeric composites are made into a standard polymer production process. These processes include molding, extrusion, injection molding, resin transfer molding, and vacuum transfer, just to name a few. This well-developed process of production techniques has already shown that it produces high-quality composite materials [36].

\subsection{Effect of Particle Size on Wear of Composites}

Nanoparticle fillers are a method to improve the wear resistance of polymers. Nanoparticles introduced into the matrix improve the toughness, leading to reduced wear by sub-surface fatigue. The nanoparticle has lower angularity, it reduces abrasiveness; improve reinforcement of the polymer matrix, due to enhanced mechanical properties of nanoparticles, such as strength, modulus, and toughness; higher specific surface areas and thus, improved adhesion. A lot of studies have been conducted based on nanotechnology. Particle filled polymer composites have significant characteristics in the development of wear-resistant materials. Nanoparticle polymer composite is a new type of material, with a very low filling amount the material properties showed to be improved. The high specific surface area is the most attractive characteristic of nanoparticles, because it produces a large number of interfacial phases in the composites, thus forming

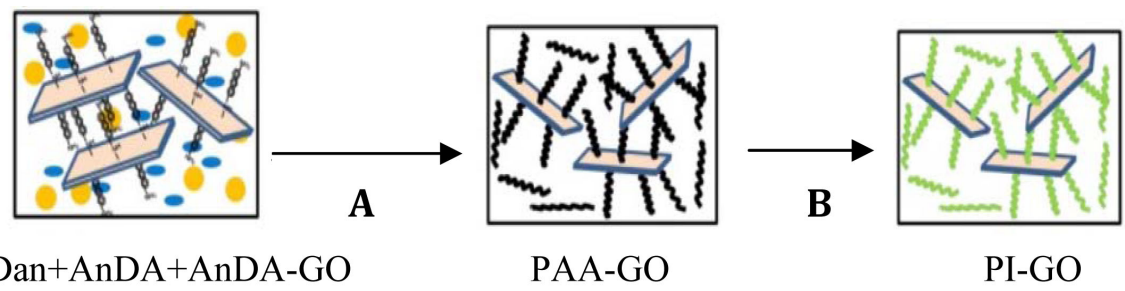

Figure 2. PI-GO Preparation, A: In situ polymerization method, B: Chemical imidization method. 
a strong interaction between the matrix and the filler under very low nanofiller loading [37]. Richard et al. revealed that the tribological properties of composites were greatly affected by the particle size as well as particle content. The wear rate of a polyester matrix reinforced by ultrafine biochar with a particle size of $45 \mathrm{~nm}$ reduced to about $56.36 \%$ than cured pure resin. The friction coefficient of the same sample is $6.42 \%$ reduction as compared with the cured resin [38]. Olea Mejia et al. studied the wear mechanism of polymer with different metals. Wear mechanisms of low-density polyethylene (LDPE), depending on the type and size of the metal particles used. The wear rate of LDPE was significantly reduced by the addition of $\mathrm{Al}$ (micron and nano) particles. The outcomes indicated that the wear rate of Ag with either micro- and nano-particle filled and Ni nanocomposites are better than that of nanocomposites. By comparing, they concluded that nanoparticles as well dispersed reduced wear than that of micro-particles [39]. Chauhan et al. explored the effect of particle size on the friction and wear properties of vinyl ester composites. Three different sizes of cenosphere particles $(2 \mu \mathrm{m}, 900 \mathrm{~nm}$, and $400 \mathrm{~nm}$ diameter) were used. Comparatively submicron size of cenosphere particles greatly plays a contribution to wear resistance improvement than microparticles. The findings revealed that $6 \mathrm{wt} \%$ submicron particle content tends to reduce the wear rate, friction coefficient also decrease proportionally to the decrease of particle size content of the composites. In addition, under a high normal load of $70 \mathrm{~N}$ and a sliding speed of $5.7 \mathrm{~m} / \mathrm{s}$, submicron hollow microspheres $(400 \mathrm{~nm})$ are the most effective antifriction fillers. Under normal load, a decrease of particle size consequently decreases the specific wear rate (Figure 3 ). The specific wear rate of the composite filled with submicron $(400 \mathrm{~nm}$ ) hollow microspheres was the lowest. Both vinyl particles and submicron particles filled with nanoparticles can enhance the wear resistance and mechanical properties of the composites. Compared with micron particles, submicron particles are more adequate in enhancing wear resistance [40]. Bernd Wetzel et al. studied the effect of particle size on the mechanical and tri-

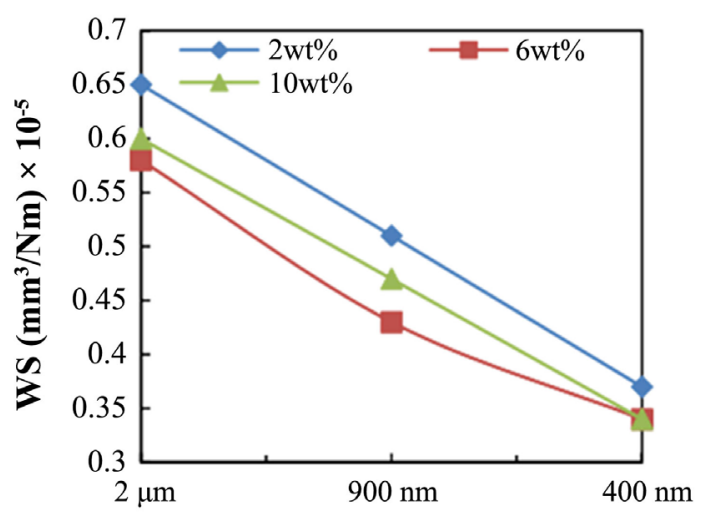

Filler size

(a)

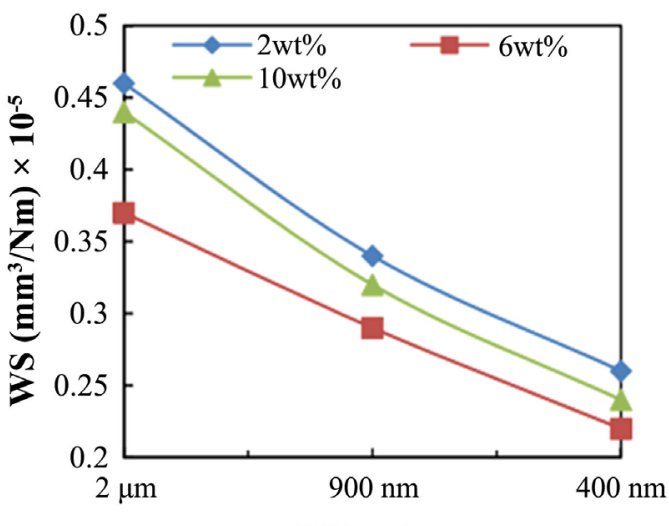

Filler size

(b)

Figure 3. Variation of specific wear rate with filler size of (a) normal load applied, $10 \mathrm{~N}$ and $1.9 \mathrm{~m} / \mathrm{s}$ and (b) normal load applied $70 \mathrm{~N}$, and $5.7 \mathrm{~m} / \mathrm{s}$ [40]. 
bological properties of polymer composites. Toughness, wear, friction, and stiffness properties of the composites are affected by the dispersion state, particle size, shape, and content. Different micro and nano-ceramic particles (calcium silicate, $\mathrm{CaSiO}_{3}, 4$ - $15 \mu \mathrm{m}$, alumina, $\mathrm{Al}_{2} \mathrm{O}_{3}, 13 \mathrm{~nm}$ ) were introduced into the epoxy resin matrix as reinforcing fillers. In general, ceramic nanoparticles can lower the wear rate matrix of epoxy resin. However, this largely depends on the content of fillers and morphology of particles. The findings indicated that the volume fraction of nanoparticles is beneficial to the agglomeration tendency, and its tribological properties were the best [41].

\section{Friction and Wear of the Polyimide/Graphene Composites}

High-performance polymer-based friction materials are becoming more and more important to enhance the mechanical output performance of materials. PI as a high-performance polymer combined with graphene and graphene derivatives has shown great improvements in tribological properties. Different studies show that the properties of the composites are greatly improved by the addition of GO. Liu, H. et al. developed PI/GO composites by using in situ polymerization of the monomer method. With the addition of GO, the friction coefficient of PI/GO composite decreased significantly. When the content of GO was $3 \%$, the composites compared to pure PI showed a decrease of $26.3 \%$ in friction coefficients. When the GO content is below $3.0 \mathrm{wt} \% \mathrm{PI} / \mathrm{GO}$ composites exhibit a decreased tendency of wear rate in dry sliding; then the wear rate increase with the increase of the GO content. The wear rate changes of PI/GO composite with 3 $\mathrm{wt} \% \mathrm{GO}$ is $21.3 \%$ reduction. Meanwhile, the addition of GO to PI improved the tribological properties [34]. Li et al. examined GO modified as incorporated into $\mathrm{PI}$, different contents of GO were generated and studied their effect comparing to pure PI, the outcomes revealed that the tensile stress as well Young's modulus of $0.5 \mathrm{wt} \%$ modified GO/PI are $27.2 \%$ and $28.0 \%$ higher than those of pure PI respectively. Therefore the addition of modified GO, the friction coefficient, and the wear rate of the material was reduced. The friction coefficient of composites tends to decrease with the increase GO contents, by adding $0.5 \mathrm{wt} \%$ modified GO the composites produced lower friction coefficient and wear rate respectively [42]. Xing et al. studied the friction and wear behavior of Catecholated graphene (G-Cat)-filled polyimide, G-Cat/PI WAS synthesized via thermal amidation. The findings indicated that G-Cat can effectively enhance the comprehensive properties of PI. As a consequence of G-Cat addition, the friction behavior of composites dramatically changes. As the content of G-Cat is $1.0 \%$, the friction coefficient of the composites reaches the lowest value of 0.38 , which is $21 \%$ lower than that of pure PI. The addition of graphene significantly improves the friction and wear properties of PI. With the marvelous properties of composites, it's found that plays a wide potential to wear resistance and lubrication applications [43]. PI and its composites are usually applied in different lubricated conditions such as drying sliding, water-lubricated, and oil-lubricated each one exhibits 
changes to composite materials.

\subsection{Tribological Properties under Drying Sliding Condition}

Polyimide composite has good self-lubricating properties and can be used in dry friction without lubrication. Recently, PI composite applications in tribology have shown great progress, friction parts designed, and proved to have improved properties. Adding graphene, carbon fiber, glass fiber, and other reinforcements into the polyimide matrix can remarkably improve the load-carrying capacity and durability of polyimide, and form the interface between polyimide and metal friction pair. Ye et al. studied under dry condition fluorinated graphene (FG) coupled with polyimide composite effects on tribological properties. A variety of portions FG were added into PI, a tribological test carried out where findings indicated that by addition $0.5 \mathrm{wt} \%$ FG tends to modify positively the tribological properties of PI matrix. The increases in FG contents slightly change the coefficient of friction of the FG/PI composite matrix, and also wear rate first decreases and then increases. The $0.5 \mathrm{wt} \% \mathrm{FG}$ corresponded to $0.87 \times 10^{-5} \mathrm{~mm} / \mathrm{N} \cdot \mathrm{m}$ wear rate which is the lowest and almost $37.4 \%$ reduction as compared to neat PI $\left(1.39 \times 10^{-5} \mathrm{~mm}^{3} / \mathrm{N} \cdot \mathrm{m}\right)$. The size changes of wear surface and debris also reflect similar results [44]. Li et al. reported the friction and wear properties of PI composites with different functional graphene contents under sliding conditions. Various monomer such as 4,9,10-tetracarboxylic dianhydride (PTCDA), perylene-3, and graphene sheets uniform introduced into PI matrix revealed the great impact on the composite whereby the coefficient of friction as well wear rates tend to decrease. Moreover, the minimum friction coefficient showed to be 0.23 while the wear rate was $1.31 \times 10^{-5} \mathrm{~mm}^{3} / \mathrm{N} \cdot \mathrm{m}$ and their respective correspondences value were $32.4 \%$ and $33.5 \%$, decreases compared to the pure PI $\left(0.34,1.97 \times 10^{-5} \mathrm{~mm}^{3} / \mathrm{N} \cdot \mathrm{m}\right)$ [45]. Su et al. investigated Surface-Modified Graphene Filled Carbon Fabric/Polyimide Composites tribological behavior. The tests were conducted basis on under sliding conditions, reinforcement of $\mathrm{MG}$ tend to reveal a lower wear rate compared to undefiled CF/PI composite. Moreover, with $1 \mathrm{wt} \% \mathrm{MG}$ content into CF/PI composites produced exceptional tribological properties, where wear rate reduced by $74 \%$ than that of the neat CF/PI composite [46]. Yuanshi et al. have studied GO and nano- $\mathrm{MoS}_{2}$-filled polyimide (PI) polymer composites properties. Under the $6 \mathrm{~N}$ load, tribological behaviors were evaluated. Outcomes indicated that GO addition particularly decrease the wear rate and friction coefficient of PI composite. The friction coefficient and running-in period of graphene oxide/nano- $\mathrm{MoS}_{2}$ (GMS)/PI composites were dramatically reduced by the addition of GMS. The average friction coefficient of 0.5 GMS/PI composites decreased by about $25 \%$ less than the neat PI, from 0.45 to 0.34 . However, when the load of GMS reaches $1 \mathrm{wt} \%$, the decrease of friction coefficient decreases, and the fluctuation of the friction coefficient curve increases, which implies that the accumulation of overload GMS plates weakens the self-lubricating effect. The addition of $0.5 \mathrm{GO} / \mathrm{PI}$ reduced the friction coeffi- 
cient to about $17 \%$ and $0.5 \mathrm{MoS}_{2} / \mathrm{PI}$ by $6 \%$ [47]. S. Zhou et al. studied the tribological properties of polyimide reinforced by fluo rographene. Under the sliding condition, when the content of FG is $0.5 \%$, the specific wear rate of $0.5 \mathrm{FG} / \mathrm{PI}$ decreased by $51.2 \%$ less than pure PI [48]. Different graphene derivatives showed to enhance the tribological properties as reinforced polyimide composites.

\subsection{Tribological Properties under Water-Lubricated Condition}

Water-lubricated tribology is a new branch of tribology, which is being established and developed. In the seawater environment, the pump, open hydraulic transmission system, and blades of the ship will be exposed to the seawater during operation. Thus, due to oil leakage and high corrosiveness of seawater, the liquid lubricant cannot provide sufficient lubrication effect. To expand the service life of mechanical parts and lowering the maintenance cost of parts, mechanical parts are demanded to have good tribological properties and excellent seawater corrosion resistance. Therefore, it is very significant to research and develop new self-lubricating materials for seawater. Compared with metals and ceramics, polymer matrix composites showed the advantages of good corrosion resistance, strong environmental adaptability, and excellent tribological properties, which can meet the requirements of the seawater environment [49] [50] [51]. Polyimide has good thermal stability, excellent mechanical and electrical properties, high chemical inertness, as well as high energy radiation resistance. However, has worse tribological properties, it cannot be widely used in lubricating materials. Go has been widely concerned in the study of lubrication and mechanical properties. The introduction of PI shows excellent tribological properties under different conditions. Min et al. Examined the friction coefficient and wear rate of $\mathrm{PI} / \mathrm{GO}$ nanocomposite under seawater lubrication condition. In particular, the reinforced PI composite with $0.5 \mathrm{wt} \%$ GO had shown the best wear resistance. Consequently, GO addition changed dramatically thermal stability, tensile stress, and tensile modulus of the composites materials. With incredible properties, PI/GO formed showed a potential use as a candidate for tribological applications in water lubrication. Figure 4 showed the film of composites comparative for dry friction and seawater lubrication. Under different lubricating conditions (Figure 5) showed the comparative of friction coefficient and wear rate of PI/GO composites against sliding time [51]. Ye et al. prepared Fluorinated graphene (FG) by a simple hydrothermal reaction and introduced into PI composites. The tribological properties of PI and FG/PI were studied under water lubrication. The tribological properties of the composite of FG nanofiller coupled with PI are better than that of neat PI. In the range of $0.5 \mathrm{FG}$ content, the wear rate of FG/PI increased from $2.41 \times 10^{-4} \mathrm{~mm}^{3} / \mathrm{N} \cdot \mathrm{m}$ for the unfilled PI to $1.51 \times 10^{-4} \mathrm{~mm}^{3} / \mathrm{N} \cdot \mathrm{m}$ FG/PI [44]. Li et al. developed graphene sheets (GNs) and PTCDA to reinforce PI. Underwater lubrication condition, the tribological properties of composite material dramatically changed. $1 \mathrm{mg}$ of GNS and PTCDA contents weighted and filled Pi composites, findings indicated the 


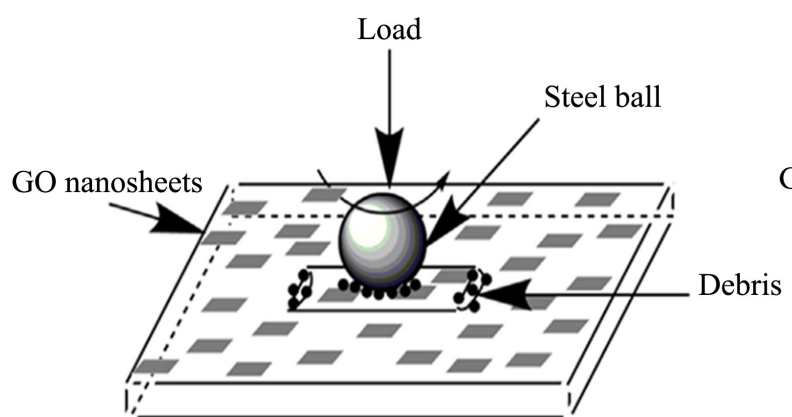

(a)

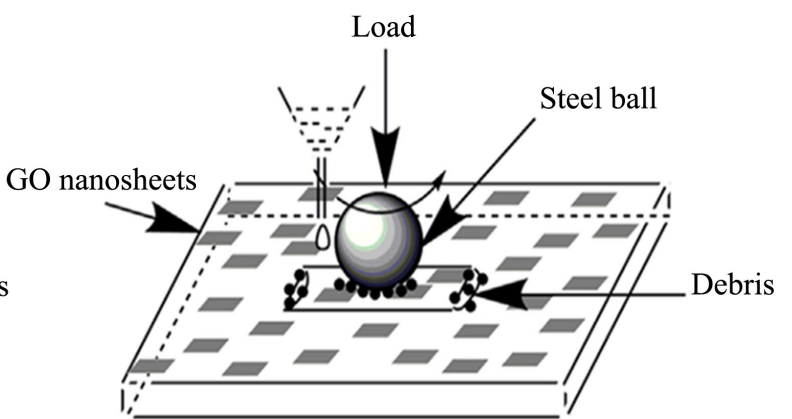

(b)

Figure 4. PI and PI/GO nanocomposites film for tribological applications (a) under dry friction and (b) under seawater lubrication [51].

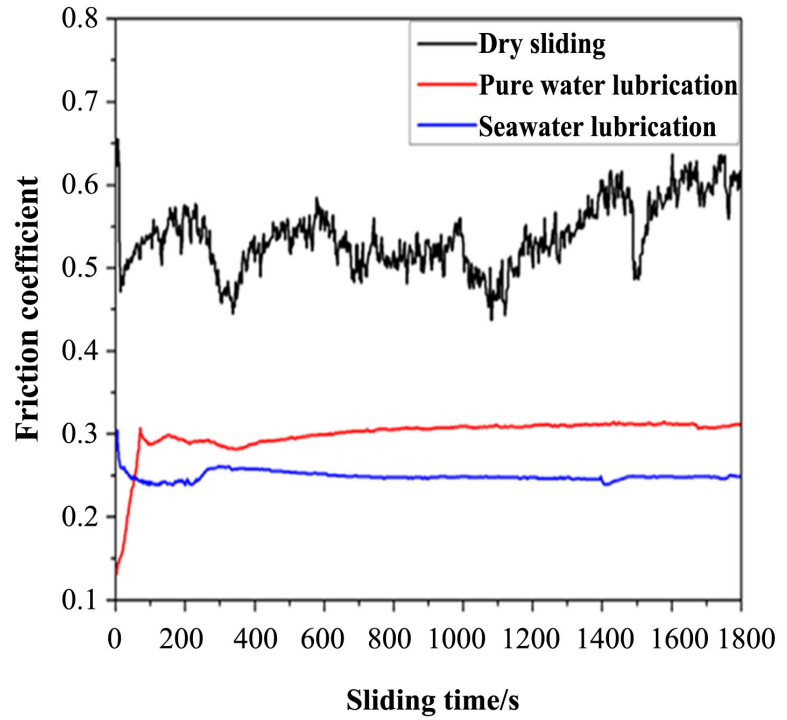

(a)

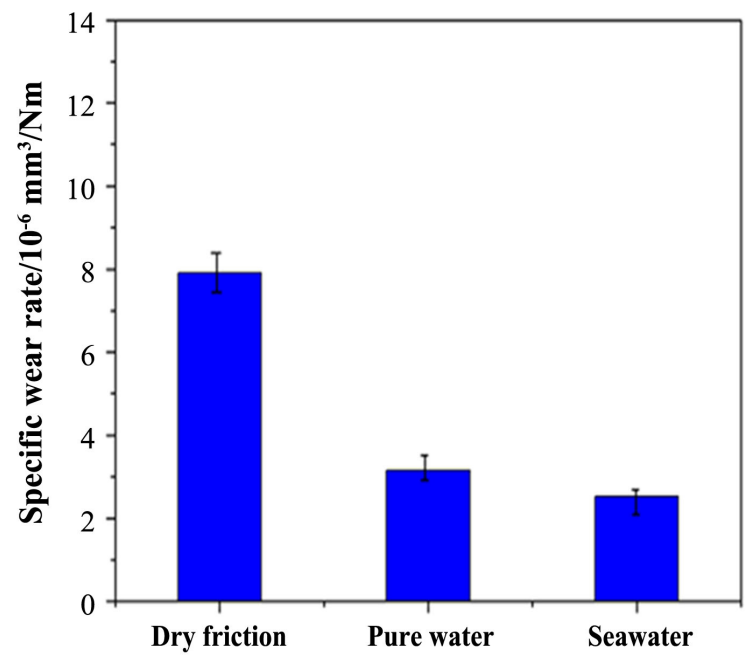

(b)

Figure 5. Coefficients of friction Variation (a) and specific wear rate (b) of PI/GO composites (load: $3 \mathrm{~N}$, sliding speed: $0.1569 \mathrm{~m} / \mathrm{s}$, Duration: $30 \mathrm{~min}$ ) [51].

great change in friction coefficient as well as wear rate for composites materials were decreased by $69 \%$ and $45 \%$ respectively. Finally, various amounts of GNS and PTCDA filled into PI produced a material with anti-wear and friction reduction aspects [45].

\subsection{Tribological Properties under Oil-Lubricated Condition}

It has been proved that lubricating oil helps to form a lubricating film, thereby reducing friction, the friction and wear properties of polymer and polymer composites, under oil-lubricated conditions still rare. Friction can't be avoided in mechanical equipment, add lubricating oil between relatively moving parts tends in reducing friction and produce anti-wear in-between. Ye et al. showed that under oil-lubricated conditions, the addition of FG significantly improved the wear resistance of PI, and the friction coefficient slightly decreased. In particular, the minimum wear rate of PI/FG-0.5 is $1.42 \times 10^{-6} \mathrm{~mm}^{3} / \mathrm{N} \cdot \mathrm{m}$, which is 
$61.1 \%$ lower than that of unfilled PI $\left(3.65 \times 10^{-6} \mathrm{~mm}^{3} / \mathrm{N} \cdot \mathrm{m}\right)[44]$.

\subsection{Influence of Nanofillers on Tribological Properties of Polyimide-Graphene Composites}

PI composites properties can be oriented by hybridizing with fillers, which have attracted several researchers. Different Nanofillers, such as $\mathrm{MoS}_{2}, \mathrm{Al}_{2} \mathrm{O}_{3}, \mathrm{BN}$, $\mathrm{TiO}_{2}, \mathrm{SiO}_{2}$, and so on, filled polymer composites also show outstanding mechanical, thermal, and tribological properties [52] [53] [54] [55] [56]. Especially has improved the properties of PI composites. Chen et al. investigated the Synergistic effect of amines fillers such as ethylenediamine (EG), diethylenetriamine (DG), and p-phenylenediamine (PG) decorated functioned graphene and introduced to PI. Using in situ polymerization method, different amine-functioned graphene oxide (AFG) contents were introduced into the PI matrix. Different materials characterizations were conducted and results showed great improvement in the mechanical and thermal properties. Moreover, DG was introduced into PI composites whereby friction coefficient decreased and consequently affects the wear rate which tended to be improved accordingly. Within 1.0 DG volume fraction stimulated the good friction coefficient which is about $51.9 \%$ decreased compared to neat PI. At the same filled content, the wear rate was produced with a minimum value which about $46.3 \%$ decrease from neat PI [57]. Wang et al. studied the nano $\mathrm{CuO}$ and graphite modified polyimide (PI) composites. Comparatively the findings revealed that the tribological properties were improved. Various types of conditions were investigated the addition of nano- $\mathrm{CuO}$ and graphite, firstly under dry sliding condition indicated wore tribological properties $\left(0.32\right.$ and $\left.1.31 \times 10^{-6} \mathrm{~mm}^{3} / \mathrm{N} \cdot \mathrm{m}\right)$, while under oil lubrication condition friction coefficient as well wear rate significantly improved (0.05 and $\left.0.15 \times 10^{-6} \mathrm{~mm}^{3} / \mathrm{N} \cdot \mathrm{m}\right)$, lastly underwater lubrication condition worse properties of tribology were found [58]. Liu et al. examined graphene oxide and nano $\mathrm{SiO}_{2}$ effects reinforced PI. Using the in-situ polymerization method nano-SiO ${ }_{2}, \mathrm{GO}$ and nano- $\mathrm{SiO}_{2} / \mathrm{GO}$ hybrid reinforced thermosetting polyimide (TPI) composites were produced. The tribological outcomes showed that the nano- $\mathrm{SiO}_{2} / \mathrm{GO} / \mathrm{TPI}$ hybrid composites have better wear-resistant, particularly under high load than TPI. Incorporated of either $\mathrm{GO}$ or nano- $\mathrm{SiO}_{2}$ into TPI revealed a better wear rate compared to neat TPI, the average friction coefficient of $0.5 \%$ nano- $\mathrm{SiO}_{2} / \mathrm{GO} / \mathrm{TPI}$ composite is the smallest, and the wear resistance of $0.4 \%$ nano- $\mathrm{SiO}_{2} / \mathrm{GO} / \mathrm{TPI}$ composite was the best. As many factors affect the tribological properties of polymer matrix composites, nanofillers proved to strengthen the properties of composites; nano- $\mathrm{SiO}_{2}$ and $\mathrm{GO}$ had greatly improved tribological properties under high load [59]. Furthermore, Liu et al. examined the $\mathrm{Fe}_{2} \mathrm{O}_{3}$ nanofiller effect introduced into reduced graphene oxide (RGO) for reinforcing PI matrix, therefore the tribological of $\mathrm{PI} / \mathrm{RGO} / \mathrm{Fe}_{2} \mathrm{O}_{3}$ composites showed great improvements as compared to pure PI. The Tribological Mechanism study revealed that $\mathrm{Fe}_{2} \mathrm{O}_{3}$ modified RGO has a strong synergistic effect and interface force, which is helpful for its high-performance antifriction formation. These results provided a 
new perspective for the study of $\mathrm{Fe}_{2} \mathrm{O}_{3}$ modified RGO and its polyimide composites, and a way for graphene oxide (GO) based composites as compression and wear-resistant solid fillers and lubricants when polymer composites required excellent compression, tribological, and thermal properties. Different contents of $\mathrm{RGO} / \mathrm{Fe}_{2} \mathrm{O}_{3}$ were introduced into PI, $0.75 \mathrm{wt} \% \mathrm{RGO} / \mathrm{Fe}_{2} \mathrm{O}_{3}$ exhibited the lowest wear rate and friction properties were good at high loading conditions. The combinational of RGO and $\mathrm{Fe}_{2} \mathrm{O}_{3}$ significantly improved the friction and wear of composites [60]. Hong Ruan et al. investigated ionic liquid with functioned graphene (ILFG) synergistic effect reinforced PI. Using the $\pi$ - $\pi$ stacking interface ILFG/PI was produced with different ILFG contents, using plate-on-ring apparatus tribological properties were investigated. Comparing to pure PI values of friction coefficient and wear rate showed improvement under dry conditions, only $0.4 \mathrm{wt} \%$ ILFG/PI exhibited excellent friction coefficient and wear rate by about decreasing of $38.2 \%$ and $25 \%$ respectively. Moreover, other properties such as tensile strength and modulus dramatically improved by about $51.9 \%$ and $56.5 \%$ more than that of pure PI respectively [61].

\section{Friction and Wear of the Polyimide/Carbon Fibers Composites}

To improve the tribological behavior of the pure polyimide, the reinforced phases, lubricating additions, and/or nanoparticles were added to improve the wear rate and friction coefficient. Introducing carbon fibers into PI composites increases the compressive strength, loading capacity, mechanical strength, and wear resistance of composites.

\subsection{Tribological Properties under Dry Sliding Condition}

Carbon fiber (CF) has been used to reinforce PI under different conditions and showed marvelous improvements in properties. Chen et al. studied the tribological properties of short carbon as reinforced PI composites for different conditions. Under dry conditions, the results showed, compared with glass-fibers and quartz-fiber strengthened polyimide composites short-carbon-fiber has the best mechanical properties. As a good reinforcement material, CF coupled polyimide not only proved to have excellent tensile and modulus but also decrease friction coefficient and wear rate. CF composites materials promising to be considered for tribological application by replacing traditional materials [62]. Li et al. studied Carbon Fiber Reinforced Polyimide Composites friction and wear properties. To further improve the performance of PI materials to meet the practical application needs, the carbon fiber reinforced method has become an effective way to improve the performance of PI materials. For example, through the addition of carbon fiber, the wear resistance of PI composite under dry sliding conditions is improved. Experiments showed that with the increase of carbon fiber volume fraction, the wear resistance of PI composite first increases and then decreases. When the volume fraction of carbon fiber is $20 \%$, PI composite presents the exceptional wear resistance property. The friction coefficient is directly pro- 
portional to the load applied and tends to be inversely proportional to sliding frequency. While the volumetric wear of neat PI and CF/PI composites increases with the increase of load and reciprocating sliding frequency [63]. Cai et al. investigated the tribological properties of short carbon fiber reinforced polyimide composites. The results showed that carbon fiber significantly changes the tribological properties of PI composites. The addition of carbon fiber can reduce the friction coefficient of the PI composite and improve the wear resistance of the composite [64]. Wang et al. evaluated the CF reinforced PI tribological behavior; results showed that short CF and graphite (Gr) enhance PI composites by improving tribological properties. Different filler's contents greatly reduced friction, whereby the addition of nano- $-\mathrm{Si}_{3} \mathrm{~N}_{4}$ as a single filler showed worse wear resistance of the PI composite. By coupling more than one filler, such as nano-Si $\mathrm{N}_{4}$, short carbon fibers (SCF), and Gr with PI composites showed excellent tribological properties. Nano- $\mathrm{Si}_{3} \mathrm{~N}_{4} / \mathrm{SCF} / \mathrm{Gr} / \mathrm{PI}$ composites under dry showed good friction and wear properties of 0.13 and $1.3 \times 10^{-6} \mathrm{~mm} / \mathrm{N} \cdot \mathrm{m}$ respectively [65]. Zhang et al. studied the tribological properties of short carbon fiber (SCFS), micron $\mathrm{SiO}_{2}$, and graphite ( $\mathrm{Gr}$ ) particles reinforced polyimide. Each kind of filler changed the properties of PI composites (Table 1), the single addition of Gr and SCF significantly improved the tribological properties of PI composites; on the other hand, the friction and wear properties of PI composites deteriorated with the addition of a micro amount of $\mathrm{SiO}_{2}$. The composite of Gr, SCF, and micron $\mathrm{SiO}_{2}$ can greatly improve the friction and wear properties of PI composites. PI-10\% Gr-10\% SCF-3\% $\mathrm{SiO}_{2}$ showed the best friction coefficient (0.18) and wear rate $\left(0.85 \times 10^{-6} \mathrm{~mm}^{3} / \mathrm{N} \cdot \mathrm{m}\right)$ [66]. Song et al. studied the improvement of the properties of Polyimide Composites by nano and micro reinforcement. To improve the mechanical and Tribological Properties of polyimide (PI), hydroxylated carbon nanotubes (CNTs) were chemically added to the surface of carbon fiber (CF). The microstructure and fracture morphology of polyimide composites showed that CF-CNTs can be uniformly distributed in the polyimide matrix as a multi-scale reinforcement. A coupled CF-CNTs hybrid showed to affect different properties by increasing hardness, friction reduction, and better wear resistance.

Table 1. PI composites under the dry sliding condition friction coefficient and wear rate values at $200 \mathrm{~N}$ load and $0.43 \mathrm{~m} / \mathrm{s}$ sliding speed [66].

\begin{tabular}{cccc}
\hline Codes & Composites & Friction coefficient & Wear rate $/ 10^{-6} \mathrm{~mm}^{3} / \mathrm{Nm}$ \\
\hline PI & Neat PI & 0.4 & 3.85 \\
PI-1 & PI-3\% $\mathrm{SiO}_{2}$ & 0.39 & 12 \\
PI-2 & PI-10\% Gr & 0.3 & 2.9 \\
PI-3 & PI-10\% SGF & 0.27 & 2.66 \\
PI-4 & PI-10\% Gr-3\% SiO 2 & 0.25 & 1 \\
PI-5 & PI-10\% Gr-10\% SCF & 0.24 & 0.9 \\
PI-6 & PI-10\% SCF-3\% SiO & 0.28 & 7.23 \\
PI-7 & PI-10\% Gr-10\% SCF-3\% $\mathrm{SiO}_{2}$ & 0.18 & 0.85 \\
\hline
\end{tabular}


15 wt\% CF-CNT hybrids introduced to PI exhibited the best wear rate and friction coefficient with a decrement of about $23.2 \%$ and $55.9 \%$, respectively. Moreover, high load and velocity can also result in friction reduction and wear rate decrease. The CF-CNTs/PI composite showed excellent wear resistance under high load and velocity, which can broaden their application in the field of high PV condition [67]. Chen et al. examined the effects of multi-scale carbon fiber-carbon nanotube (CF-CNT) on tribological properties of PI composites. Using chemical method CF-CNT was produced and introduced into PI composites. Results indicated that CF filler improved tribological properties especially decrease wear of PI composites, acid-CF, and CF-CNT, they also found to improve PI tribological properties. Under the dry condition, $4.5 \mathrm{~N}$ Load was applied with $0.083 \mathrm{~m} / \mathrm{s}$ sliding speed, PI/CF showed an increased friction coefficient (0.319) and decrease of wear rate $\left(3.98 \times 10^{-6} \mathrm{~mm}^{3} / \mathrm{N} \cdot \mathrm{m}\right)$ while PI/CF-CNT produced an excellent wear rate $\left(1.799 \times 10^{-6} \mathrm{~mm}^{3} / \mathrm{N} \cdot \mathrm{m}\right)$ and decreasing in friction coefficient (0.213) [68]. Zhao et al. studied the friction and wear properties of polyimide with different fibers. Carbon, glass, and aramid were used as fibers to reinforce PI, under dry conditions results were proven that reinforcement significantly affects the tribological properties of PI composites. CF/PI indicated the lowest coefficient of friction; while the glass fiber reinforced PI exhibited a higher compared to other fibers. Wear resistance showed an improvement as PI composites reinforced by fibers, either carbon or glass fibers [69]. Zhu et al. investigated the tribological properties of PI/carbon nanofibers nanocomposites. The mechanical and Tribological Properties of PI/carbon nanofibers nanocomposites were investigated by adding untreated carbon nanofibers (CNFs (U)) and treated CNFs (T) as fillers. The tribological properties of PI/CNFs (U) and PI/CNFs (T) composites were studied. Load and sliding speed slightly changed the material properties especially their increasing makes friction coefficient of composites decreased, while a lower wear rate was gained for both PI/CNFs (u) and PI/CNFs ( $\mathrm{t}$ ) composites as compared to neat PI [70]. Qi et al. studied PI composites properties particularly tribological as coupled with different particles including PTFE, aramid fiber (AP), and carbon fiber (SCF). Reinforcement fillers and film formation effects on tribological behavior were also examined. Comparatively, each filler changes positively material properties compared to unfilled PI composite. AP seems to have under dry conditions good properties of tribology than SCF when every single one is coupled with PI composites. SCF reinforced PI revealed to exhibit excellent wear rate and good friction coefficient comparing to pure PI. Moreover, tribological mechanisms of reinforced fillers were connected to the interaction between fillers and matrix [71]. Su et al. studied the influences of $\mathrm{SiC}$ nanoparticles filled carbon fabric/Polyimide Composites on the tribological properties. The preparation of $\mathrm{SiC}$ nanoparticles coupled carbon fabric/Polyimide was conducted using dip-coating and hot press molding methods. Under dry condition, friction and wear, characteristics were studied using ring-on-block contact mode. SiC nanoparticles had a significant effect on the wear rate of the CF/PI composite but have a little effect on the friction coef- 
ficient. A different contents value of $\mathrm{SiC}$ nanoparticles were arranged into composites, 1 vol\% $\mathrm{SiC}$ nanoparticles were incorporated into the $\mathrm{CF} / \mathrm{PI}$ composite and reduction of the wear rate was found. When SiC nanoparticles increased to $5 \mathrm{vol} \%$ the lowest wear rate $\left(0.96 \times 10^{-6} \mathrm{~mm}^{3} / \mathrm{N} \cdot \mathrm{m}\right)$ was obtained which is about a $70 \%$ reduction compared to the unfilled composite [72].

\subsection{Tribological Properties under Water-Lubricated Condition}

Carbon fibers also showed great changes when incorporated with PI composites under the water-lubricated condition for different properties of materials. Chen et al. reported the synergistic effect of carbon series addition into PI composites. Under the seawater-lubricated condition, different series of carbon fibers, carbon nanotubes, and graphite introduced to PI composites, tribological behaviors were studied. Every single filler indicated that can enhance the wear resistance of composites. i.e. PI-10\%Gr showed a decrease in wear rate $\left(11.4 \times 107 \mathrm{~mm}^{3} / \mathrm{N} \cdot \mathrm{m}\right)$ which almost 6 times in reduction comparing to neat PI $(69.3 \times 107 \mathrm{~mm} / \mathrm{N} \cdot \mathrm{m})$, PI-10\%CF indicated an excellent reduction of wear rate $\left(8.12 \times 107 \mathrm{~mm}^{3} / \mathrm{N} \cdot \mathrm{m}\right)$ which is about 8 times reduction by comparing to neat PI, CNT also proved to improve wear rate, the addition of PI-5\%CNT by comparing to neat PI reduced wear rate $\left(16.4 \times 107 \mathrm{~mm}^{3} / \mathrm{N} \cdot \mathrm{m}\right)$ by 4 times. When coupled all fillers at different contents volume also showed better wear resistance, the lowest occurred at PI-10\%CF-10\%Gr-5\%CNT $\left(3.72 \times 107 \mathrm{~mm}^{3} / \mathrm{N} \cdot \mathrm{m}\right)$ which is about 18 times reduction comparing to pure PI. Moreover, each carbon series played great roles in enhancing the wear resistance of PI composites; their combined properties tend to produce materials with excellent tribological behaviors under high load (200N) [73]. Min et al. studied the effect of carbon spheres on the mechanical and thermal properties of polyimide by the in-situ polymerization method. Also, by the lubrication effect of seawater which proved to be good compared to other conditions, the friction coefficient produced by the synthesis of PI and carbon spheres composites showed to be lower than that of other conditions. Various volume contents of carbon spheres were introduced into PI composites, $0.7 \mathrm{wt} \%$ $\mathrm{PI} /$ carbon sphere composites under seawater lubrication indicated the lowest coefficient of friction. Wear rate was also conducted under different lubricating conditions, where seawater lubrication conditions exhibited worse than other conditions due to its microstructure defects [74]. Qi et al. studied the effects of seawater lubrication on the tribological properties of PI composites containing SCF and PTFE. Seawater as a good lubricant affects the results of tribological properties, combining excellent properties of SCF and PTFE also enhance the friction and wear properties [71]. Wu et al. investigated PI coupled with carbon fibers (CF) under distilled water condition tribological properties. CF volume fraction added into polyimide composites and has been shown a lower friction coefficient than those of neat polyimide. Different carbon fibers sizes such as 100 $\mu \mathrm{m}, 300 \mu \mathrm{m}, 1000 \mu \mathrm{m}$ were examined accordingly. By comparing $100 \mu \mathrm{m}$ carbon fiber showed a lower wear rate, as well as friction coefficients than those of polyimide composites, contained $300 \mu \mathrm{m}$ and $1000 \mu \mathrm{m}$ carbon fibers. Within 1000 
$\mu \mathrm{m}$ carbon fiber addition into Polyimide matrix composite whereby different loads and sliding speeds were applied, the findings indicated the highest specific wear rate [75].

\subsection{Tribological Properties under Oil-Lubricated Condition}

Oil-lubricated condition plays also great effects on the tribological properties of composites. Zhao et al. under oil lubrication, studied tribological characteristics as $\mathrm{ZnS}$ sub-micrometer particles and reinforcing fibers incorporated into the PI matrix. Compositions of PI-based materials (Table 2) were used to evaluate friction and wear properties. Different fibers such as Short carbon fibers (SCF), short glass fibers (SGF) were decorated with $\mathrm{ZnS}$ sub-micrometer particle, and then introduced to PI composite. Figure 6 showed characteristics changes of friction coefficient and wear rate due to loading and sliding speed, meanwhile, the effect of fillers was investigated. Comparisons were made accordingly; SGF and SCF significantly improved the friction and wear of composites material. The combination of SGF and ZnS particles also reduced the friction coefficient. As a single filler, SGF showed a low wear rate compared to others. Moreover $\mathrm{ZnS} / \mathrm{SGF} / \mathrm{PI}$ proved to have excellent wear resistance comparing to any single filler. The hybrid composite ZnS/SGF/PI also showed to be promising for tribological application under oil lubrication conditions [76].

\section{Research Challenges}

Graphene and CF-based polymer composites have been receiving significant attention lately because of their interesting and useful characteristics, such as good mechanical properties, tribological, and electrical. Due to quality and good performance, they showed to be considered as a replacement for traditional materials. Nevertheless, challenges still exist, for examples:

1) Disparities in different material properties of commercial graphenes, such as size, structure, and purity which affect the expected results [77].

2) The processing and manufacturing technologies of graphene and carbon fiber-based polymer composites are insufficient in quality and commercial value [78] [79].

3) Fabrication of materials depends on different parameters such as the con-

Table 2. Compositions of PI-based materials (vol \%) [76].

\begin{tabular}{ccccc}
\hline $\begin{array}{c}\text { Sample } \\
\text { Abbreviation }\end{array}$ & Matrix & $\begin{array}{c}\text { Short carbon fibers } \\
\text { (SCF) }\end{array}$ & $\begin{array}{c}\text { short glass fibers } \\
\text { (SGF) }\end{array}$ & $\begin{array}{c}\text { ZnS sub-micrometer } \\
\text { particle }\end{array}$ \\
\hline PI & 100 & - & - & - \\
ZnS/PI & 95 & - & - & 5 \\
SCF/PI & 90 & 10 & - & - \\
SGF/PI & 90 & - & 10 & - \\
ZnS/SCF/PI & 85 & 10 & - & 5 \\
ZnS/SGF/PI & 85 & - & 10 & 5 \\
\hline
\end{tabular}



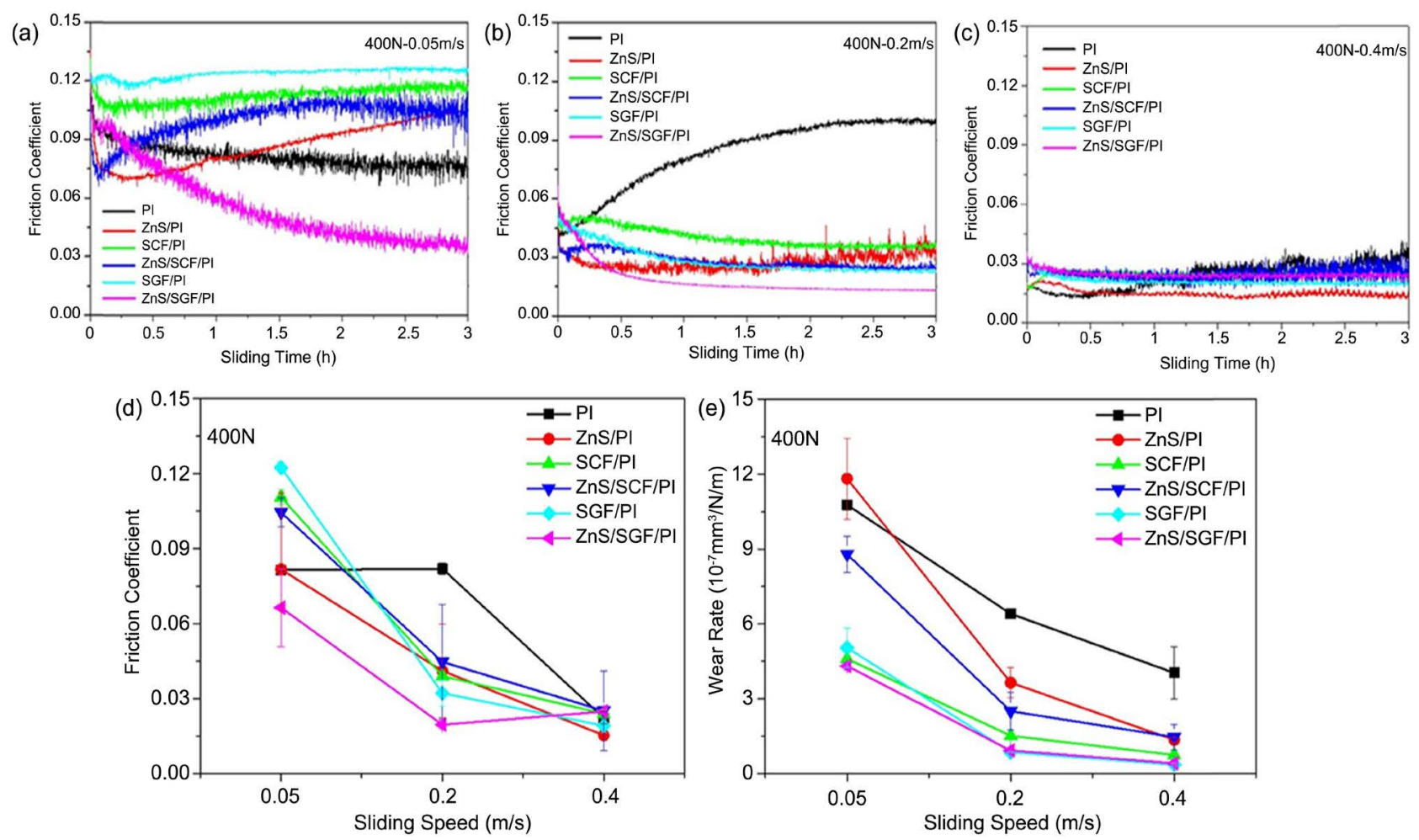

Figure 6. Friction coefficients against sliding time at various speeds (a-c); mean friction coefficients and wear rates (d and e) of PI-based materials against sliding speeds. Applied load: $400 \mathrm{~N}$ [76].

tents of fillers types of fillers and selective methods. Furthermore, to obtain quality products, different aspects require a lot of attention such as manufacturing technologies, processing techniques, structure properties, and quality control of starting materials [80].

4) Technical barriers include structure control, matrix dispersion of graphene, interfacial interaction between graphene and matrix, and individual contact of graphene [81].

5) The manufacturing cost of graphene-based or carbon fiber-based composites is high because of the high energy consumption in the manufacturing process [79] [82].

6) Lack of exact physical properties for standards graphene characterization and safety protocols for a selective application [83].

7) Specific guidelines and regulations, experimental schemes, and established safety practices for the disposal of derived wastes are lacking [83].

8) Inadequate data are available on graphene composites for high-performance structural applications, as well as interface properties between graphene and polymer matrix under severe loading conditions.

9) At present, there is no graphene-modified composites model for high-performance structure, which makes it difficult to design graphene composite structures which can provide good mechanical properties and provide predictable and safe failure modes [84]. 
10) Lack of knowledge about the potential risks of graphene and CF-based materials to human health or the environment. CF can cause respiratory system problems and skin diseases [85] [86].

11) The high loading of CF as introduced to polymer lead to the formation of weak and brittle composites [87].

12) The preparation of carbon fiber matrix composites is very difficult. Due to the rod-shaped characteristics of carbon fiber, a higher matrix volume fraction is needed to achieve compact packaging. Also, the pores in the matrix filled with CF will lead to the formation of voids, which will eventually affect the mechanical properties of the composites [82].

\section{Conclusion}

With comparative tribological properties under different conditions graphene/ polyimide and carbon fibers/polyimide were reviewed, and each composite exhibit tremendous properties. The special structure and excellent properties of graphene make it a great application value in the friction field. Different lubricants, lubricating films, and wear-resistant materials can be prepared. The modification of graphene and its derivatives prepared with various contents $\%$ introduced into polymer composites have become one of the hot research topics. As polyimide itself has some defects, such as poor antistatic performance and high wear rate, limit its further application in high-performance fields. The addition of graphene into polyimide can give the composite different functional properties (not only excellent mechanical and electrical properties but also excellent tribological properties). Different contents values of derivatives graphene coupled polyimide play a great role to enhance the properties of composites. Tribological properties were reviewed, by increasing contents values composites showed an excellent reduction in friction coefficient as well as wear rate under dry, water, and oil-lubricated conditions. Furthermore, other nanofillers were introduced as decorating graphene derivatives such as nano- $\mathrm{CuO}$, nano- $\mathrm{SiO}_{2}$, $\mathrm{Fe}_{2} \mathrm{O}_{3}$, etc, and proved to have a great impact on tribological improvements of composite material. The experimental outcomes showed that the selection of suitable fillers and the modification of fillers play an important role in improving the tribological properties of the composites. Carbon fibers have become the forefront material to reinforce polymers. Introduced to polyimide showed great achievements whereby mechanical, electrical, and tribological properties of polyimide significantly increased under various conditions. Different more nanofiller also coupled with carbon fibers to enhance the tribological properties of polyimide and considerably improved to a high extent. Therefore this review is aimed to provide the understanding of the tribological properties under various conditions of graphene as introduced into polyimide as well as that of carbon fibers coupled with polyimide. Moreover this review also revealed that these materials composites could be considered as replacement of traditional materials in tribological applications. 


\section{Conflicts of Interest}

The authors declare that they have no conflict of interest.

\section{References}

[1] Luong, N.D., Hippi, U., Korhonen, J.T., Soininen, A.J., Ruokolainen, J., Johansson, L.S., Nam, J.D., Le, H.S. and Seppälä, J. (2011) Enhanced Mechanical and Electrical Properties of Polyimide Film by Graphene Sheets via in Situ Polymerization. Polymer, 52, 5237-5242. https://doi.org/10.1016/j.polymer.2011.09.033

[2] Zhu, J., Lim, J., Lee, C.H., Joh, H.I., Kim, H.C., Park, B., You, N.H. and Lee, S. (2014) Multifunctional Polyimide/Graphene Oxide Composites via in Situ Polymerization. Journal of Applied Polymer Science, 131, 40177. https://doi.org/10.1002/app.40177

[3] Ye, X., Wang, J., Xu, Y., Niu, L., Fan, Z., Gong, P., Ma, L., Wang, H., Yang, Z. and Yang, S. (2015) Mechanical Properties and Thermostability of Polyimide/Mesoporous Silica Nanocomposite via Effectively Using the Pores. Journal of Applied Polymer Science, 131, 205-212. https://doi.org/10.1002/app.41173

[4] Shi, Y., Mu, L., Feng, X. and Lu, X. (2011) Tribological Behavior of Carbon Nanotube and Polytetrafluoroethylene Filled Polyimide Composites under Different Lubricated Conditions. Journal of Applied Polymer Science, 121, 1574-1578. https://doi.org/10.1002/app.33696

[5] Wu, G., Cheng, Y., Wang, Z., et al. (2017) In Situ Polymerization of Modified Graphene/Polyimide Composite with Improved Mechanical and Thermal Properties. Journal of Materials Science: Materials in Electronics, 28, 576-581. https://doi.org/10.1007/s10854-016-5560-8

[6] Papageorgiou, D.G., Kinloch, I.A. and Young, R.J. (2017) Mechanical Properties of Graphene and Graphene-Based Nanocomposites. Progress in Materials Science, 90, 75-127. https://doi.org/10.1016/j.pmatsci.2017.07.004

[7] Dike, A.S. (2019) Improvement of Mechanical and Physical Properties of Carbon Fiber-Reinforced Polyamide Composites by Applying Different Surface Coatings for Short Carbon Fiber. Journal of Thermoplastic Composite Materials, 33, 541-553. https://doi.org/10.1177/0892705719877218

[8] Liu, L., Zhou, M., Jin, L., Li, L., Mo, Y., Su, G. and Tian, Y. (2019) Recent Advances in Friction and Lubrication of Graphene and Other 2D Materials: Mechanisms and Applications. Friction, 7, 199-216. https://doi.org/10.1007/s40544-019-0268-4

[9] Sun, J. and Du, S. (2019) Application of Graphene Derivatives and Their Nanocomposites in Tribology and Lubrication: A Review. RSC Advances, 9, 40642-40661. https://doi.org/10.1039/C9RA05679C

[10] Fu, L., Liao, K., Tang, B., Jiang, L. and Huang, W. (2020) Applications of Graphene and Its Derivatives in the Upstream Oil and Gas Industry: A Systematic Review. Nanomaterials, 10, 1013. https://doi.org/10.3390/nano10061013

[11] Ha, Y., Kim, Y.N., Kim, Y., et al. (2020) Enhanced Mechanical Properties and Thermal Conductivity of Polyimide Nanocomposites Incorporating Individualized Boron-Doped Graphene. Carbon Letters, 30, 457-464. https://doi.org/10.1007/s42823-019-00115-y

[12] Lee, Y.M., You, J., Kim, M., Kim, T.A., Lee, S.-S., Bang, J. and Park, J.H. (2019) Highly Improved Interfacial Affinity in Carbon Fiber-Reinforced Polymer Composites via Oxygen and Nitrogen Plasma-Assisted Mechanochemistry. Composites Part B: Engineering, 165, 725-732. 
https://doi.org/10.1016/j.compositesb.2019.02.021

[13] Dong, F., Hou, G., Liu, H., Liu, L., Cao, F., Wang, J. and Yan, F. (2017) An Investigation on the Mechanical and Tribological Properties of Carbon Fiber/Polyimide Composites at Elevated Temperatures. Polymer Composites, 39, E869-E882.

https://doi.org/10.1002/pc.24290

[14] Das, T.K., Ghosh, P. and Das, N.C. (2019) Preparation, Development, Outcomes, and Application Versatility of Carbon Fiber-Based Polymer Composites: A Review. Advanced Composites and Hybrid Materials, 2, 214-233. https://doi.org/10.1007/s42114-018-0072-Z

[15] Hutchings, I., Gee, M. and Santner, E. (2006) Friction and Wear. In: Czichos, H., Saito, T. and Smith, L., Eds., Handbook of Materials Measurement Methods, Springer, Berlin, 685-710. https://doi.org/10.1007/978-3-540-30300-8_13

[16] Ma, Y., Liu, Y., Ma, S., Wang, H., Gao, Z., Sun, J. and Guo, L. (2014) Friction and Wear Properties of Dumbbell-Shaped Jute Fiber-Reinforced Friction Materials. Journal of Applied Polymer Science, 131, 40748. https://doi.org/10.1002/app.40748

[17] Ma, Y., Liu, Y., Shang, W., Gao, Z., Wang, H., Guo, L. and Tong, J. (2014) Tribological and Mechanical Properties of Pine Needle Fiber Reinforced Friction Composites under Dry Sliding Conditions. RSC Advances, 4, 36777.

https://doi.org/10.1039/C4RA06717G

[18] Zhai, D., Shui, Y., Feng, K. and Zhang, Y. (2019) Effects of Rare-Earth Oxides on the Microstructure and Properties of Fe-Based Friction Materials Synthesized by in Situ Carbothermic Reaction from Vanadium-Bearing Titanomagnetite Concentrates. RSC Advances, 9, 20687-20697. https://doi.org/10.1039/C9RA03271A

[19] Dyachkova, L.N. and Feldshtein, E.E. (2015) Microstructures, Strength Characteristics and Wear Behavior of the Fe-Based P/M Composites after Sintering or Infiltration with Cu-Sn Alloy. Journal of Materials Science and Technology, 31, 1226-1231. https://doi.org/10.1016/j.jmst.2015.10.007

[20] Merie, V., Cândea, V., Bîrleanu, C., Păşcuță, P. and Popa, C. (2012) The Influence of Titanium Dioxide on the Tribological Characteristics of a Fe-Based Friction Composite Material. Journal of Composite Materials, 48, 235-243. https://doi.org/10.1177/0021998312470152

[21] Zhang, F., Chu, Y. and Li, C. (2019) Fabrication and Tribological Properties of Copper Matrix Solid Self-Lubricant Composites Reinforced with Ni/NbSe2 Composites. Materials, 12, 1854. https://doi.org/10.3390/ma12111854

[22] Schwartz, C.J. and Bahadur, S. (2000) Studies on the Tribological Behavior and Transfer Film-Counterface Bond Strength for Polyphenylene Sulfide Filled with Nanoscale Alumina Particles. Wear, 237, 261-273. https://doi.org/10.1016/S0043-1648(99)00345-2

[23] Bahadur, S. and Sunkara, C. (2005) Effect of Transfer Film Structure, Composition, and Bonding on the Tribological Behavior of Polyphenylene Sulfide Filled with Nanoparticles of TiO2, ZnO, CuO, and SiC. Wear, 258, 1411-1421. https://doi.org/10.1016/j.wear.2004.08.009

[24] Zhang, Z., Yang, L., Wu, X., Li, C. and Wang, F. (2019) Comparative Evaluation on Friction and Wear Characteristics of $\mathrm{SiC}, \mathrm{Si}_{3} \mathrm{~N}_{4}, \mathrm{Al}_{2} \mathrm{O}_{3}$, and $\mathrm{ZrO}_{2}$ Sliding against Peek Composite for Seawater Hydraulic Axial Piston Pumps. The Journal of Engineering, 2019, 362-366. https://doi.org/10.1049/joe.2018.9031

[25] Dass, K., Chauhan, S. and Gaur, B. (2013) Mechanical and Dry Sliding Wear Characterization of Microsize Silicon Carbide and Aluminum Oxide-Filled Ortho Cresol Novalac Epoxy Composites. Journal of Composite Materials, 48, 2747-2759. 
https://doi.org/10.1177/0021998313502065

[26] Tiwari, S.K., Sahoo, S., Wang, N.N. and Huczko, A. (2020) Graphene Research and Their Outputs: Status and Prospect. Journal of Science: Advanced Materials and Devices, 5, 10-29. https://doi.org/10.1016/j.jsamd.2020.01.006

[27] Yang, G., Li, L., Lee, W.B. and Ng, M.C. (2018) Structure of Graphene and Its Disorders: A Review. Science and Technology of Advanced Materials, 19, 613-648. https://doi.org/10.1080/14686996.2018.1494493

[28] Geim, A.K. and Novoselov, K.S. (2007) The Rise of Graphene. Nature Materials, 6, 183-191. https://doi.org/10.1038/nmat1849

[29] Neto, A.C., Guinea, F. and Peres, N.M. (2006) Drawing Conclusions from Graphene. Physics World, 19, 33-37. https://doi.org/10.1088/2058-7058/19/11/34

[30] Jacob, A. (2014) Carbon Fiber and Cars: 2013 in Review. Reinforced Plastics, 58, 18-19. https://doi.org/10.1016/S0034-3617(14)70036-0

[31] Newcomb, B.A. (2016) Processing, Structure, and Properties of Carbon Fibers. Composites Part A: Applied Science and Manufacturing, 91, 262-282. https://doi.org/10.1016/j.compositesa.2016.10.018

[32] Meng, F., McKechnie, J., Turner, T., Wong, K.H. and Pickering, S.J. (2017) Environmental Aspects of the Use of Recycled Carbon Fiber Composites in Automotive Applications. Environmental Science and Technology, 51, 12727-12736. https://doi.org/10.1021/acs.est.7b04069

[33] Zhang, L., Tu, S., Wang, H. and Du, Q. (2018) Preparation of Polymer/Graphene Oxide Nanocomposites by a Two-Step Strategy Composed of in Situ Polymerization and Melt Processing. Composites Science and Technology, 154, 1-7. https://doi.org/10.1016/j.compscitech.2017.10.030

[34] Liu, H., Li, Y., Wang, T. and Wang, Q. (2011) In Situ Synthesis and Thermal, Tribological Properties of Thermosetting Polyimide/Graphene Oxide Nanocomposites. Journal of Materials Science, 47, 1867-1874. https://doi.org/10.1007/s10853-011-5975-9

[35] Choi, J.-Y., Yu, H.-C., Lee, J., Jeon, J., Im, J., Jang, J. and Chung, C.-M. (2018) Preparation of Polyimide/Graphene Oxide Nanocomposite and Its Application to Nonvolatile Resistive Memory Device. Polymers, 10, 901.

https://doi.org/10.3390/polym10080901

[36] Ho, M.-P., Wang, H., Lee, J.-H., Ho, C.-K., K-T, L., Leng, J. and Hui, D. (2012) Critical Factors on Manufacturing Processes of Natural Fibre Composites. Composites Part B, 43, 3549-3562. https://doi.org/10.1016/j.compositesb.2011.10.001

[37] Wang, Q. and Pei, X. (2008) The Influence of Nanoparticle Fillers on the Friction and Wear Behavior of Polymer Matrices. Tribology and Interface Engineering Series, 55, 62-81. https://doi.org/10.1016/S1572-3364(08)55004-X

[38] Richard, S., Selwin Rajadurai, J. and Manikandan, V. (2016) Effects of Particle Loading and Particle Size on Tribological Properties of Biochar Particulate Reinforced Polymer Composites. Journal of Tribology, 139, Article ID: 012202. https://doi.org/10.1115/1.4033131

[39] Olea-Mejia, O., Brostow, W. and Buchman, E. (2010) Wear Resistance and Wear Mechanisms in Polymer + Metal Composites. Journal of Nanoscience and Nanotechnology, 10, 8254-8259. https://doi.org/10.1166/jnn.2010.3026

[40] Chauhan, S.R. and Thakur, S. (2013) Effects of Particle Size, Particle Loading and Sliding Distance on the Friction and Wear Properties of Cenosphere Particulate Filled Vinylester Composites. Materials and Design, 51, 398-408. 
https://doi.org/10.1016/j.matdes.2013.03.071

[41] Wetzel, B., Haupert, F. and Zhang, M. (2003) Epoxy Nanocomposites with High Mechanical and Tribological Performance. Composites Science and Technology, 63, 2055-2067. https://doi.org/10.1016/S0266-3538(03)00115-5

[42] Li, D., Yang, W., Chen, Y., Xiao, C. and Wei, M. (2018) Effect of Modified Graphene on Thermal, Mechanical and Tribological Performance of Polyimide Based Composites. Materials Research Express, 5, Article ID: 065304. https://doi.org/10.1088/2053-1591/aac686

[43] Wu, X., Jin, Z., Zhu, Y. and Zhao, H. (2020) Catecholated Graphene-Filled Polyimide with Enhanced Mechanical, Thermal, and Tribological Properties. High Performance Polymers. https://doi.org/10.1177/0954008320940358

[44] Ye, X., Liu, X., Yang, Z., Wang, Z., Wang, H., Wang, J. and Yang, S. (2016) Tribological Properties of Fluorinated Graphene Reinforced Polyimide Composite Coatings under Different Lubricated Conditions. Composites Part A: Applied Science and Manufacturing, 81, 282-288. https://doi.org/10.1016/j.compositesa.2015.11.029

[45] Li, Y., Zhang, Q., Ruan, H., Li, F., Xu, X., Huang, X. and Lu, S. (2019) Improving the Tribological and Mechanical Properties of Polyimide Composites by Incorporating Functionalized Graphene. High Performance Polymers. https://doi.org/10.1177/0954008319847260

[46] Su, C., Xue, F., Xu, F., Li, T., Xin, Y. and Wang, M. (2019) Tribological Properties of Surface-Modified Graphene Filled Carbon Fabric/Polyimide Composites. Journal of Macromolecular Science, Part B, 58, 1-16. https://doi.org/10.1080/00222348.2019.1614276

[47] Xin, Y., Li, T., Gong, D., Xu, F. and Wang, M. (2017) Preparation and Tribological Properties of Graphene Oxide/Nano- $\mathrm{MoS}_{2}$ Hybrid as Multidimensional Assembly Used in the Polyimide Nanocomposites. RSC Advances, 7, 6323-6335. https://doi.org/10.1039/C6RA27108A

[48] Zhou, S., Li, W., Zhao, W., Liu, C., Fang, Z. and Gao, X. (2019) Tribological Behaviors of Polyimide Composite Films Enhanced with Fluorographene. Colloids and Surfaces A: Physicochemical and Engineering Aspects, 580, Article ID: 123707. https://doi.org/10.1016/j.colsurfa.2019.123707

[49] Friedrich, K. (2018) Polymer Composites for Tribological Applications. Advanced Industrial and Engineering Polymer Research. https://doi.org/10.1016/j.aiepr.2018.05.001

[50] (1992) Chapter Five the Classification and Applications of Liquid Lubricants. Tribology Series, 23, 408-663. https://doi.org/10.1016/S0167-8922(08)70352-3

[51] Min, C., Nie, P., Song, H.-J., Zhang, Z. and Zhao, K. (2014) Study of Tribological Properties of Polyimide/Graphene Oxide Nanocomposite Films under SeawaterLubricated Condition. Tribology International, 80, 131-140. https://doi.org/10.1016/j.triboint.2014.06.022

[52] Liu, B., Pei, X., Wang, Q., Sun, X. and Wang, T. (2011) Effects of Atomic Oxygen Irradiation on Structural and Tribological Properties of Polyimide/ $\mathrm{Al}_{2} \mathrm{O}_{3}$ Composites. Surface and Interface Analysis, 44, 372-376. https://doi.org/10.1002/sia.3814

[53] Panin, S.V., Duc Anh, N., Kornienko, L.A., Alexenko, V.O., Buslovich, D.G. and Ovechkin, B.B. (2018) Wear-Resistant Polyetheretherketone Composites. Materials Today: Proceedings, 5, 25976-25982. https://doi.org/10.1016/j.matpr.2018.08.015

[54] Yu, J., Zhao, W., Wu, Y., Wang, D. and Feng, R. (2018) Tribological Properties of Epoxy Composite Coatings Reinforced with Functionalized C-BN and H-BN Nano- 
fillers. Applied Surface Science, 434, 1311-1320.

https://doi.org/10.1016/j.apsusc.2017.11.204

[55] Uflyand, I.E., Zhinzhilo, V.A. and Burlakova, V.E. (2019) Metal-Containing Nanomaterials as Lubricant Additives: State-of-the-Art and Future Development. Friction, 7, 93-116. https://doi.org/10.1007/s40544-019-0261-y

[56] Ali, M.K.A., et al. (2016) Improving the Tribological Characteristics of Piston Ring Assembly in Automotive Engines Using $\mathrm{Al}_{2} \mathrm{O}_{3}$ and $\mathrm{TiO}_{2}$ Nanomaterials as $\mathrm{Na}$ no-Lubricant Additives. Tribology International, 103, 540-554. https://doi.org/10.1016/j.triboint.2016.08.011

[57] Chen, Y., Li, D., Yang, W., Xiao, C. and Wei, M. (2018) Effects of Different Amine-Functionalized Graphene on the Mechanical, Thermal, and Tribological Properties of Polyimide Nanocomposites Synthesized by in Situ Polymerization. Polymer, 140, 56-72. https://doi.org/10.1016/j.polymer.2018.02.017

[58] Wang, Q., Zhang, X. and Pei, X. (2010) A Synergistic Effect of Graphite and Nano-CuO on the Tribological Behavior of Polyimide Composites. Journal of Macromolecular Science, Part B, 50, 213-224. https://doi.org/10.1080/00222341003641156

[59] Liu, H., Jia, Y., Wang, H., Duan, C., Wang, T. and Wang, Q. (2020) Ultra-High Compression and Wear Resistant Hybrid Filled Polyimide Composite: Synergistic Effect of $\mathrm{Fe}_{2} \mathrm{O}_{3}$ Decorated RGO. Journal of Applied Polymer Science, 137, e49222. https://doi.org/10.1002/app.49222

[60] Liu, H., Cui, X., Wang, H., Zhang, H. and Li, A. (2019) Synergistic Effect of Nano- $\mathrm{SiO}_{2}$ and Graphene Oxide: Hybrid Filled Thermosetting Polyimide Nanocomposites with Ultralow Wear. Materials Research Express, 6, Article ID: 105368. https://doi.org/10.1088/2053-1591/ab4155

[61] Ruan, H., Qiu, Z., Liao, W., et al. (2020) Enhancing Tribological, Mechanical, and Thermal Properties of Polyimide Composites by the Synergistic Effect between Graphene and Ionic Liquid. Materials and Design, 189, Article ID: 108527. https://doi.org/10.1016/j.matdes.2020.108527

[62] Chen, J., Jia, J., Zhou, H., Chen, J., Yang, S. and Fan, L. (2007) Tribological Behavior of Short-Fiber-Reinforced Polyimide Composites under Dry-Sliding and Water-Lubricated Conditions. Journal of Applied Polymer Science, 107, 788-796. https://doi.org/10.1002/app.27127

[63] Li, J. and Cheng, X. (2007) The Effect of Carbon Fiber Content on the Friction and Wear Properties of Carbon Fiber Reinforced Polyimide Composites. Journal of Applied Polymer Science, 107, 1737-1743. https://doi.org/10.1002/app.27273

[64] Cai, Z.Y. and Bao, J. (2011) The TPB and Tribological Properties of Short Carbon Fiber Reinforced Polyimide Composite. Advanced Materials Research, 299-300, 102-105. https://doi.org/10.4028/www.scientific.net/AMR.299-300.102

[65] Wang, Q., Zhang, X. and Pei, X. (2010) Study on the Synergistic Effect of Carbon Fiber and Graphite and Nanoparticle on the Friction and Wear Behavior of Polyimide Composites. Materials and Design, 31, 3761-3768.

https://doi.org/10.1016/j.matdes.2010.03.017

[66] Zhang, X.-R., Pei, X.-Q. and Wang, Q.-H. (2009) Friction and Wear Studies of Polyimide Composites Filled with Short Carbon Fibers and Graphite and Micro $\mathrm{SiO}_{2}$. Materials and Design, 30, 4414-4420. https://doi.org/10.1016/j.matdes.2009.04.002

[67] Song, J., Yu, Y., Zhao, G., Qiu, J. and Ding, Q. (2019) Improved Tribological Properties of Polyimide Composites by Micro-Nano Reinforcement. Journal of Applied Polymer Science, 136, 47900. https://doi.org/10.1002/app.47900

[68] Chen, B., Li, X., Li, X., Jia, Y., Yang, J., Yang, G. and Li, C. (2017) Friction and Wear 
Properties of Polyimide-Based Composites with a Multiscale Carbon Fiber-Carbon Nanotube Hybrid. Tribology Letters, 65, 111. https://doi.org/10.1007/s11249-017-0891-Z

[69] Zhao, G., Hussainova, I., Antonov, M., Wang, Q. and Wang, T. (2013) Friction and Wear of Fiber Reinforced Polyimide Composites. Wear, 301, 122-129. https://doi.org/10.1016/j.wear.2012.12.019

[70] Zhu, J., Mu, L., Chen, L., Shi, Y., Wang, H., Feng, X. and Lu, X. (2014) Interface-Strengthened Polyimide/Carbon Nanofibers Nanocomposites with Superior Mechanical and Tribological Properties. Macromolecular Chemistry and Physics, 215, 1407-1414. https://doi.org/10.1002/macp.201400194

[71] Qi, H., Hu, C., Zhang, G., Yu, J., Zhang, Y. and He, H. (2019) Comparative Study of Tribological Properties of Carbon Fibers and Aramid Particles Reinforced Polyimide Composites under Dry and Sea Water Lubricated Conditions. Wear, 436-437, Article ID: 203001. https://doi.org/10.1016/j.wear.2019.203001

[72] Su, C., Xue, F., Li, T., Xin, Y. and Wang, M. (2016) Study on the Tribological Properties of Carbon Fabric/Polyimide Composites Filled with SiC Nanoparticles. Journal of Macromolecular Science, Part B, 55, 627-641. https://doi.org/10.1080/00222348.2016.1179248

[73] Chen, B., Wang, J., Liu, N. and Yan, F. (2014) Synergism of Several Carbon Series Additions on the Microstructures and Tribological Behaviors of Polyimide-Based Composites under Sea Water Lubrication. Materials and Design, 63, 325-332. https://doi.org/10.1016/j.matdes.2014.06.016

[74] Min, C., Nie, P., Tu, W., Shen, C., Chen, X. and Song, H. (2015) Preparation and Tribological Properties of Polyimide/Carbon Sphere Microcomposite Films under Seawater Condition. Tribology International, 90, 175-184. https://doi.org/10.1016/j.triboint.2015.04.027

[75] Wu, J., Kou, Z. and Cui, G. (2016) The Tribological Properties of Carbon Fiber Reinforced Polyimide Matrix Composites under Distilled Water Condition. Industrial Lubrication and Tribology, 68, 212-219. https://doi.org/10.1108/ILT-05-2015-0060

[76] Zhao, F., Li, G., Zhang, G., Wang, T. and Wang, Q. (2017) Hybrid Effect of ZnS Sub-Micrometer Particles and Reinforcing Fibers on Tribological Performance of Polyimide under Oil Lubrication Conditions. Wear, 380-381, 86-95. https://doi.org/10.1016/j.wear.2017.03.007

[77] Mirabedini, A., Ang, A., Nikzad, M., Fox, B., Lau, K.-T. and Hameed, N. (2020) Evolving Strategies for Producing Multiscale Graphene-Enhanced Fiber-Reinforced Polymer Composites for Smart Structural Applications. Advanced Science, 7, Article ID: 1903501. https://doi.org/10.1002/advs.201903501

[78] An, X., Ma, J., Wang, K. and Zhan, M. (2015) Growth of Silver Nanowires on Carbon Fiber to Produce Hybrid/Waterborne Polyurethane Composites with Improved Electrical Properties. Journal of Applied Polymer Science, 133, 1-13. https://doi.org/10.1002/app.43056

[79] Müller, K., Bugnicourt, E., Latorre, M., Jorda, M., Echegoyen Sanz, Y., Lagaron, J., Schmid, M., et al. (2017) Review on the Processing and Properties of Polymer Nanocomposites and Nanocoatings and Their Applications in the Packaging, Automotive and Solar Energy Fields. Nanomaterials, 7, 74. https://doi.org/10.3390/nano7040074

[80] Li, Y., Feng, Z., Huang, L., Essa, K., Bilotti, E., Zhang, H. and Hao, L. (2019) Additive Manufacturing High Performance Graphene-Based Composites: A Review. 
Composites Part A: Applied Science and Manufacturing, 124, Article ID: 105483. https://doi.org/10.1016/j.compositesa.2019.105483

[81] Ramanathan, T., Abdala, A.A., Stankovich, S., Dikin, D.A., Herrera-Alonso, M., Piner, R.D. and Brinson, L.C. (2008) Functionalized Graphene Sheets for Polymer Nanocomposites. Nature Nanotechnology, 3, 327-331. https://doi.org/10.1038/nnano.2008.96

[82] Zhang, J., Chevali, V.S., Wang, H. and Wang, C.-H. (2020) Current Status of Carbon Fibre and Carbon Fibre Composites Recycling. Composites Part B: Engineering, 193, Article ID: 108053. https://doi.org/10.1016/j.compositesb.2020.108053

[83] Reina, G., González-Domínguez, J.M., Criado, A., Vázquez, E., Bianco, A. and Prato, M. (2017) Promises, Facts and Challenges for Graphene in Biomedical Applications. Chemical Society Reviews, 46, 4400-4416. https://doi.org/10.1039/C7CS00363C

[84] Guan, G. (2018) Literature Study of Graphene Modified Polymeric Composites.

[85] Fadeel, B., Bussy, C., Merino, S., Vázquez, E., Flahaut, E., Mouchet, F. and Bianco, A. (2018) Safety Assessment of Graphene-Based Materials: Focus on Human Health and the Environment. ACS Nano, 12, 10582-10620.

https://doi.org/10.1021/acsnano.8b04758

[86] Muller, J., Huaux, F. and Lison, D. (2006) Respiratory Toxicity of Carbon Nanotubes: How Worried Should We Be? Carbon, 44, 1048-1056.

https://doi.org/10.1016/j.carbon.2005.10.019

[87] Dhand, V., Mittal, G., Rhee, K.Y., Park, S.-J. and Hui, D. (2015) A Short Review on Basalt Fiber Reinforced Polymer Composites. Composites Part B: Engineering, 73, 166-180. https://doi.org/10.1016/j.compositesb.2014.12.011 